\title{
Effect of Rare Earth Upon As-Cast Microstructure and High Temperature Performance of ZA40 Alloy
}

\author{
Ji Jiaming ${ }^{*}, 1,2$, , Meng Guocui ${ }^{1,2}$, Lu Yuanyong ${ }^{3}$, Shao Honghong ${ }^{1,2}$ and Gu Dongqing ${ }^{1,2}$ \\ ${ }^{I}$ School of Material Science and Engineering, Jiangsu University, Zhenjiang, Jiangsu, 212013, P.R. China \\ ${ }^{2}$ Key Laboratory of High-End Structural Materials, Zhenjiang, Jiangsu, 212013, P.R. China \\ ${ }^{3}$ Zhenjiang Huitong Metal Forming Co., Ltd, Zhenjiang, Jiangsu, 212028, P.R. China
}

\begin{abstract}
In testing comparison, this study is made on the modification effect of 0.05 wt.\% La-rich rare earth (RE) upon as-cast microstructure, mechanical properties of materials at high temperatures $\left(100,150,200^{\circ} \mathrm{C}\right)$ and wear resistance under different temperatures $\left(100\right.$ and $\left.200^{\circ} \mathrm{C}\right)$ of ZA40 alloy containing Si. The addition of RE shows that it can not only effectively refine $\mathrm{Al}$-rich and $\mathrm{Cu}$-rich phase, but also reduce the amount of needle-like eutectic silicon, and then make the size of massive primary silicon phase smaller. Thus, there are the improvement of strength, ductility and wear resistance of materials at high temperature. The analyses are also conducted on the mechanism of underlying RE elements.
\end{abstract}

Keywords: High temperature performance, high temperature wear resistance, microstructure, mixed rare earth, ZA40.

\section{INTRODUCTION}

High aluminum zinc-based alloys are increasingly popular because they are characterized by higher strength and hardness, the improved wear resistance and high intrinsic damping capacity, lower coefficient and temperature difference of friction, and lower manufacturing cost [1-3]. However, there are the demerits of the low melting point and eutectic temperature of zinc and the wide range of solidification, with actual solid-phase point of about $380^{\circ} \mathrm{C}$. It causes the alloy at high-temperature to have low strength. Moreover, the solubility of Al-Zn-based $\alpha$ phase varies greatly with an increase of temperature. Without stable organization and with the limitations of the improvement to high-temperature performance, thus greatly reducing the use of high aluminum $\mathrm{Zn}$-based alloy. It is important to improve the high-temperature properties of $\mathrm{Zn}$ based alloys with the spreading applications of it $[4,5]$.

Rare earth (RE) elements are typical metals with the active chemical properties, allowing interaction with all the elements except inert gas. The strengthening effect of RE have widely been applied to the ferrous materials and the mechanism underlying this process has been studied. However, a few researches have been conducted for the effect of RE upon non-ferrous metal [6-9].

With comparative methods, the effects of RE have been investigated upon microstructure, mechanical properties and wear resistance of ZA40 alloy containing Si with $0.05 \mathrm{wt} \%$ rich-La mixed RE. The research can improve high-

*Address correspondence to this author at the School of Material Science and Engineering, Jiangsu University, Zhenjiang, Jiangsu, 212013,

P.R. China; Tel: +86-13775350390; E-mail: jijiaming@126.com temperature performances of the alloy, thereby broadening its application.

\section{EXPERIMENTAL PROCEDURES}

\subsection{Materials}

The material compositions of the ZA40 ally with 0.05 wt. $\% \mathrm{RE}$ (material A) and the ZA40 without RE (material B) are listed in Table $\mathbf{1}$.

The alloy was melted in a resistance furnace of graphite crucible ( $2.5 \mathrm{~kg}$ alloy for each furnace). The intermediate alloy melting method was utilized to decrease the melting temperature, oxidation of elements, and burning loss, while $\mathrm{RE}$ elements in the form of Al-10\% RE compounds were added. Metal (cast iron) casting method was adopted with pouring temperature of $650^{\circ} \mathrm{C}$ [9]. However, oversize coarse grains and the zinc smoke (zinc-oxide) occurred when the liquid temperature exceeded $700^{\circ} \mathrm{C}$.

\subsection{Mechanical Tests}

Specimens for the tensile tests were in a diameter of 6 $\mathrm{mm}$ and in an active gauge length of $30 \mathrm{~mm}$ according to GB4338-84 Chinese National standard. Tensile tests were conducted in a WE-100 Hydraulic Universal Testing Machine in an environmental chamber (temperature deviation $< \pm 3$ ). Specimens were heated up to 100,150 , and $200^{\circ} \mathrm{C}$ and incubated for $30 \mathrm{~min}$.

High-temperature wear test was conducted by using an MG-2000-type testing machine with a pin-on-disk apparatus. Test specimens (with size of $\Phi 6 \mathrm{~mm} \times 12 \mathrm{~mm}$ ) were cut from the high aluminum zinc-based alloy with and without RE. The wear plate material was $40 \mathrm{Cr}$ (quenching and lowtemperature tempering, 54 HRC) with a size of $\Phi 70 \mathrm{~mm} \times 10 \mathrm{~mm}$. The experiments were performed under the 
Table 1. Chemical composition of the materials [wt \%].

\begin{tabular}{|c|c|c|c|c|c|c|}
\hline Materials & Al & Cu & Mg & Si & Rare Earth & Zn \\
\hline \hline Material A & 40 & $3-5$ & 0 & $1-2$ & 0.05 & Balance \\
\hline Material B & 40 & $3-5$ & 0 & $1-2$ & 0 & Balance \\
\hline
\end{tabular}

stationary normal loads of $150 \mathrm{~N}$, and sliding speed of 150 $\mathrm{rpm}$ at 100 and $150^{\circ} \mathrm{C}$, respectively and both of them were in the states of dry friction. All the specimens were taken for the running test for $10 \mathrm{~min}$ and then steady wear-in test for $30 \mathrm{~min}$. The amounts of weight loss before and after the tests were weighed by using electronic balance E180 (with accuracy of $\pm 0.1 \mathrm{mg}$ ) in terms of weight differences of delta $\mathrm{m}$.

During the tests, JSM-7001F scanning electron microscope and Nikon-300 microscope were utilized to examine the worn surface and microstructures, so as to verify the dominant wear mechanisms.

\section{RESULTS AND DISCUSSION}

\subsection{Effects of RE on Microstructure of Material}

As-cast microstructures of materials with RE and without RE are shown in Fig. (1).

As shown in Fig. (1), the addition of RE refined the microstructures of the materials. Aluminum-based $\alpha$ dendrites of material $\mathrm{B}$ with $\mathrm{RE}(40 \mu \mathrm{m})$ were uniformly distributed in the matrix, while the particle distribution (size of approximately $20 \mu \mathrm{m}$ to $30 \mu \mathrm{m}$ ) of ZA40 alloy without RE was disordered. Due to the addition of mixed RE to ZA40 alloy; the disordered particles have formed a large number of dispersed heterogeneous cores (such as high melting point CeAl4 phase). Moreover, due to the mutual constraint of grain growth, the crystallization of the heterogeneous cores was resulting in its' difficult growth into coarse dendrites. There another merit to enrich RE element at the forefront of solid-liquid interface during solidification, thus affecting the solute redistribution and impeding the atom diffusion of the alloy. Therefore, it made more and more undercooling and

(a) Material A with RE

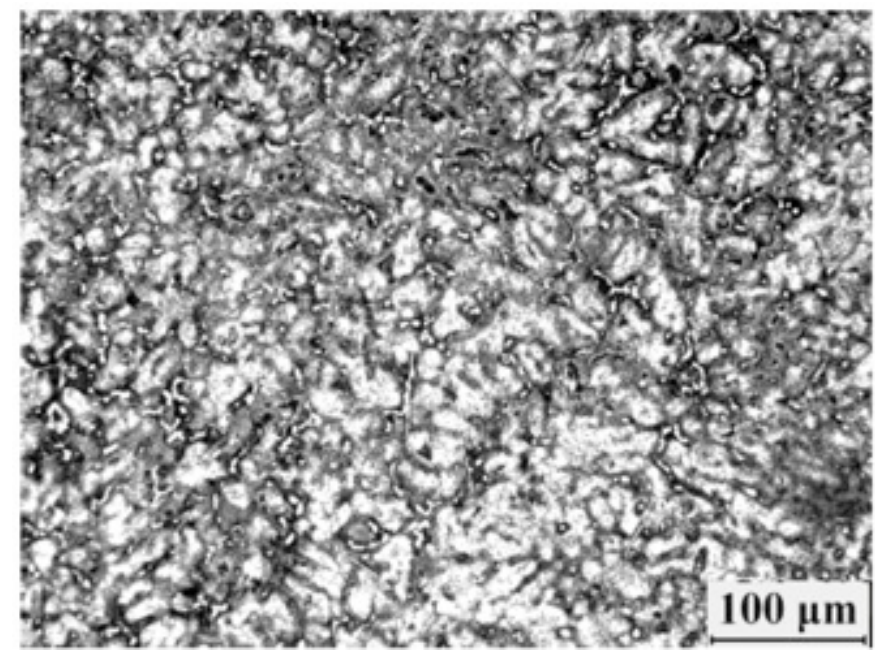

Fig. (1). As-cast microstructure of different zinc alloys. the growth of retarding $\alpha$-phase were impeded, while the wall spaces of secondary dendrite were reduced. Meanwhile, the uniform distribution of $\mathrm{Cu}$-rich phase appeared both with an increase of grain boundaries and reduction of wall spaces in the secondary dendrite.

It can be found from Fig. (1) that the morphology of $\mathrm{Si}$ phase has significantly varied. The Material B (without RE) comprised a large number of acicular eutectic silicon phases and massive primary Si phases, while the precipitation and amount of eutectic silicon phases were restrained and decreased in the number with the addition of $\mathrm{RE}$ on $\mathrm{Si}$ phases (especially on eutectic Si phase). Metamorphism of the primary Si phases was also refined.

\subsection{The Effect of Rare Earth Upon High-Temperature Mechanical Properties of Material}

Table $\mathbf{2}$ is the strength and elongation of material A with $\mathrm{RE}$, and material $\mathrm{B}$ without RE at different temperatures.

It can be observed from Table 2 that the addition of RE not only improved the strength and ductility of ZA40 containing $\mathrm{Si}$ at room temperature, but also enhanced hightemperature strength and ductility. At higher temperatures, the function of RE became more apparent.

The Strengths at ambient and elevated temperatures have been enhanced with the addition of RE. The grains at $\varepsilon$ phase and Si phase were refined since the addition of RE. With the combined action of the fine grain strengthening, dispersion strengthening and fine $\varepsilon$ phase effectively improves the tensile strength of the material. Hard Si phases (hardness of $1100 \mathrm{HV}$ ) hindered dislocation movement during the tensile process. Similarly, the presence of Si phase increases the material hardness, especially at high temperatures, and

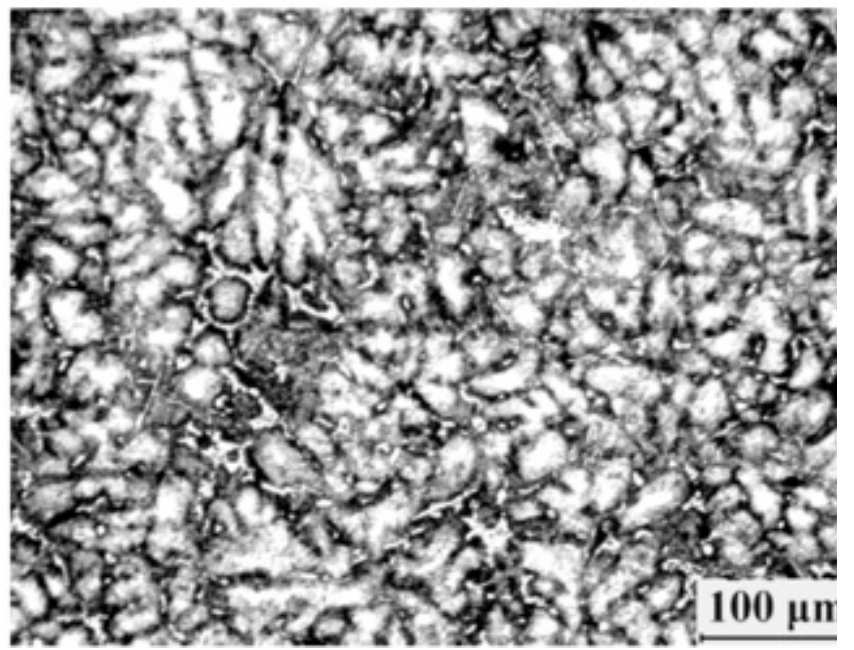


Table 2. Mechanical properties of materials at different temperatures.

\begin{tabular}{|c|c|c|c|}
\hline Material & Temperature [ ${ }^{\circ} \mathbf{C}$ ] & Yield Strength [Rm/Mpa] & Elongation A [\%] \\
\hline \hline \multirow{3}{*}{ Material A } & Room temperature & 387 & 2.82 \\
& 100 & 354.19 & 14.89 \\
27.72 & 40.92 \\
\hline \multirow{2}{*}{ Material B } & 150 & 328.48 & 2.48 \\
& 200 & 256.05 & 12.31 \\
& 377 & 22.01 \\
& 100 & 291.17 & 36.65 \\
\hline
\end{tabular}

elevates the operating temperature of the material [10].

RE compounds can improve the high temperature properties of ZA40. The matrix of ZA40 alloy mainly consists of aluminum-based solid solution and zinc-rich phase, where the solubility of RE in Al or $\mathrm{Zn}$ matrix was very limited [11]. The majority of Ce and La were associated with $\mathrm{Cu}, \mathrm{Zn}, \mathrm{Fe}$, and other elements, and $\mathrm{t}$ formed the complex compounds that exhibit the higher hardness and hot hardness even at high temperatures. During crystallization, the compounds are pushed to where dendrites and grain boundaries exist, where they hinder softening and grain boundary movement. Moreover, the melting points of RE elements are higher than those of $\mathrm{Zn}, \mathrm{Al}$ and $\mathrm{Cu}$, and much lower in the self-diffusion coefficients. Thus, RE can hinder the atomic diffusion improve the binding forces among atoms and promote high-temperature stability of the microstructure, thereby effectively improving the hightemperature strength and creep resistance of alloy [12].

The addition of $\mathrm{RE}$ in the alloy results in ductility at ambient and elevated temperatures. Grain refinement not only improves the strength, but also enhances the material's plasticity. $\varepsilon$ phase achieved the fine dispersion in the matrix, thus eliminating the overall deformation of materials caused by larger blocks and improved its plasticity. RE inhibited the growth of acicular eutectic $\mathrm{Si}$ phase precipitated in the form of primary silicon, so as to remarkably reduce the fragmentation effect on the matrix. Diversification in morphology and size of Si phase played the major role in the integration with the matrix, and also enlarged the plastic deformation of the matrix in the tensile of the materials [13].

\subsection{Effects of RE Upon High-Temperature Wear Resistance of Materials}

Table 3 is the wear test results of the experimental materials with RE (material A) and without RE (material B) at different temperatures.

In Table 3, the wear volume has significantly increased at 100 and $150^{\circ} \mathrm{C}$, compared with that at ambient temperature.
However, RE addition improved the wear resistance at both ambient and elevated temperatures.

Under $150 \mathrm{~N}$ loads at 100 and $150^{\circ} \mathrm{C}$, the surface morphologies of specimens after the wear test are as shown in Fig. (2).

Fig. (2) shows that the material with RE resulted in the abrasive wear because of the following factors. The first reason was the shedding of hard $\varepsilon$ phase and Si phase which occurred in the contact surface between the two samples during the wearing process. Secondly, RE refined the grains of $\varepsilon$ phase and $\mathrm{Si}$ phase to form the smaller abrasives. The high strength of material led to the shallow and smoothing of the furrowed edges without accumulation and grooves. This phenomenon accounts for the small volume of wear loss. However, the grooves in the material without RE became wider and glossier, and caused the distortion and cutting in the direction of wear. This is because the hard phase and Si phase were coarser, and the strength of the material without RE was relatively low and the plastic flow occurred to different extents in the front of the abrasives. The groove edges were crushed, accompanied by tearing phenomenon under the press. In addition, features of adhesive wear emerged in the local area. Thus, the volume of wear was large and the materials formed the patterns of abrasive and adhesive wear.

At $150^{\circ} \mathrm{C}$, wear surface showed almost no furrow but exhibited the varying degrees of flaking. White and black regions of RE and non-RE samples were subjected to EDS composition analyses. The results of EDS composition analysis (Table 4) show that the wear surface may be covered by the mixed oxide because of the large amount of oxygen atoms. Between black and white areas, the differences in oxygen quantity can prove that the surface exfoliation is oxide. It can be seen from this that the oxidation wear and oxide spall wear occurred in the material surface at $150^{\circ} \mathrm{C}$. In addition to oxygen atoms, $\mathrm{C}$ and $\mathrm{Fe}$ atoms were present in the worn surface. $\mathrm{Cr}$ atom was even observed on the worn surface of the alloy without RE,

Table 3. The results from wear test of material.

\begin{tabular}{|c|c|c|c|c|}
\hline & \multirow{2}{*}{ Load [N] } & Speed [rpm] & \multicolumn{2}{|c|}{ Wear Loss [g] } \\
\cline { 3 - 5 } & & & Material A & \multicolumn{2}{|c|}{ Material B } \\
\hline \hline Ambient & 150 & 150 & 0.0043 & 0.0115 \\
100 & 150 & 150 & 0.0233 & 0.0178 \\
150 & 150 & 150 & 0.0362 \\
\hline
\end{tabular}


(a) Material $\mathrm{A}, 100^{\circ} \mathrm{C}$

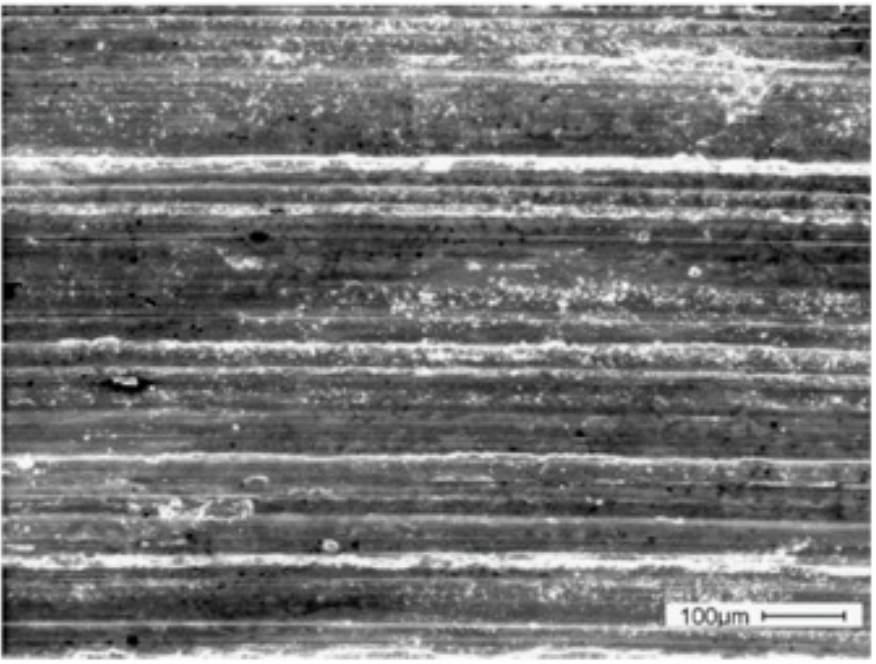

(c) Material A, $150^{\circ} \mathrm{C}$

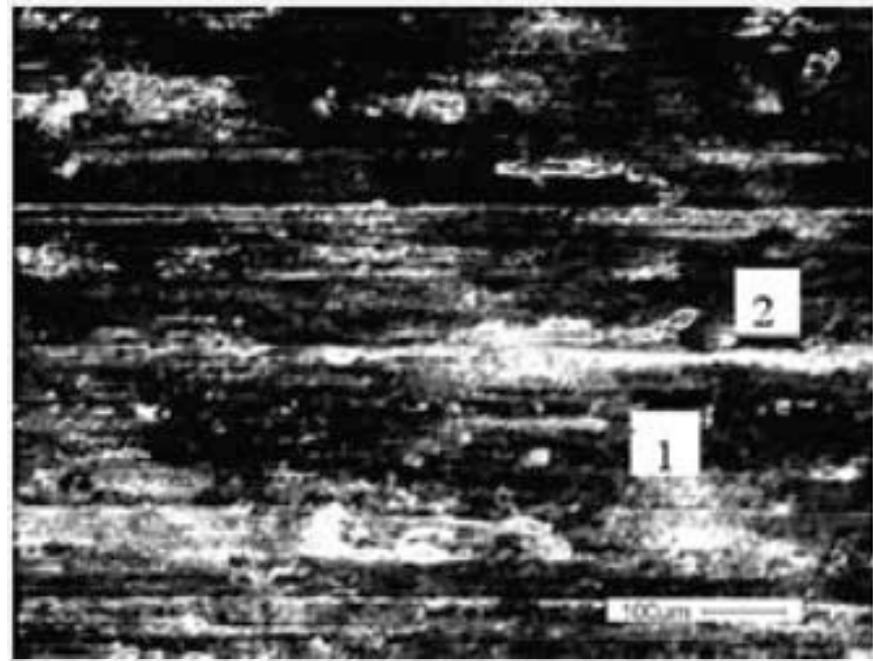

(b) Material B, $100^{\circ} \mathrm{C}$

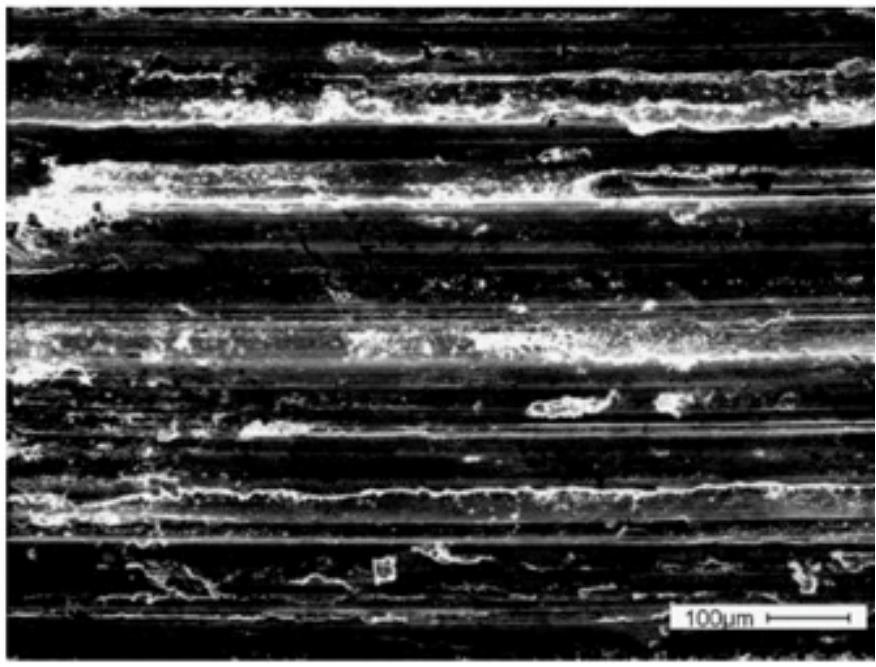

(d) Material B, $150^{\circ} \mathrm{C}$

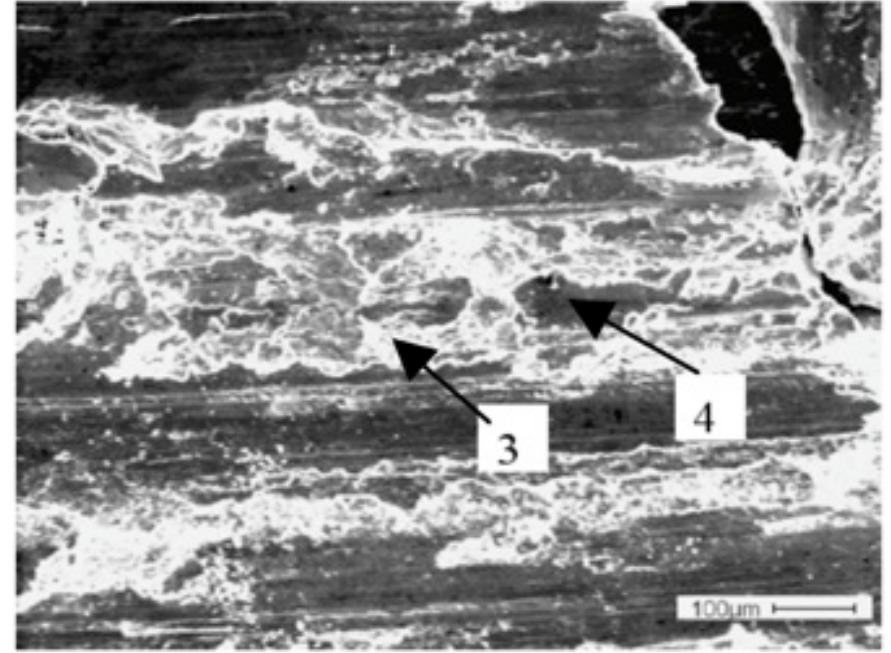

Fig. (2). Worn surface morphology at various temperatures for high aluminum zinc-based alloy with the same load and sliding speed.

obviously attributed to the wear plate material (40Gr). It is shown that $\mathrm{C}, \mathrm{Fe}$, and $\mathrm{Gr}$ were diverted during the wearing process. The degree of hardness of the surface oxide was too high, that it caused debris of the worn plate $(40 \mathrm{Cr})$ to fall on the specimen surface.

Generally, oxide films can protect the substrate and exhibit anti-friction activity. However, a matrix with the characteristics of heat resistance and thermal stability is required. The stability support of the substrate to the oxide is guaranteed during the process of wearing $[14,15]$.
Comparing Fig. (2c) with Fig. (2d), it can be easily found that the surface of the alloy without RE exhibited severe flaking, while comparing that with RE, which possesses only a small area of the shallow peeling.

Fig. (3) is the sectional morphology of the two wear specimens after wearing at $150^{\circ} \mathrm{C}$.

It can be observed from Fig. (3) that a layer of mixed oxide is different from the matrix on the surface of the samples. Due to its low matrix strength, alloy without RE cannot support the oxide layers with high hardness and at

Table 4. Composition of worn surface.

\begin{tabular}{|c|c|c|c|c|c|c|c|c|c|c|}
\hline & & \multicolumn{9}{|c|}{ Atom Percentage } \\
\hline & & Al & $\mathbf{Z n}$ & $\mathbf{C u}$ & $\mathbf{S i}$ & $\mathbf{O}$ & $\mathrm{C}$ & $\mathbf{F e}$ & $\mathbf{C r}$ & Total \\
\hline \multirow{4}{*}{$\begin{array}{c}\text { Material } \\
\text { A } \\
\text { Material B }\end{array}$} & 1 & 37.13 & 14.89 & 1.44 & 2.22 & 34.16 & 1.12 & 9.04 & 0 & 100 \\
\hline & 2 & 22.35 & 10.19 & 1.10 & 2.08 & 50.97 & 1.03 & 12.28 & 0 & 100 \\
\hline & 3 & 21.16 & 14.23 & 0.56 & 0.91 & 42.54 & 0.61 & 19.68 & 0.31 & 100 \\
\hline & 4 & 12.06 & 5.54 & 0.41 & 0.73 & 59.11 & 0.49 & 21.07 & 0.59 & 100 \\
\hline
\end{tabular}


(a) Material A at $150^{\circ} \mathrm{C}$

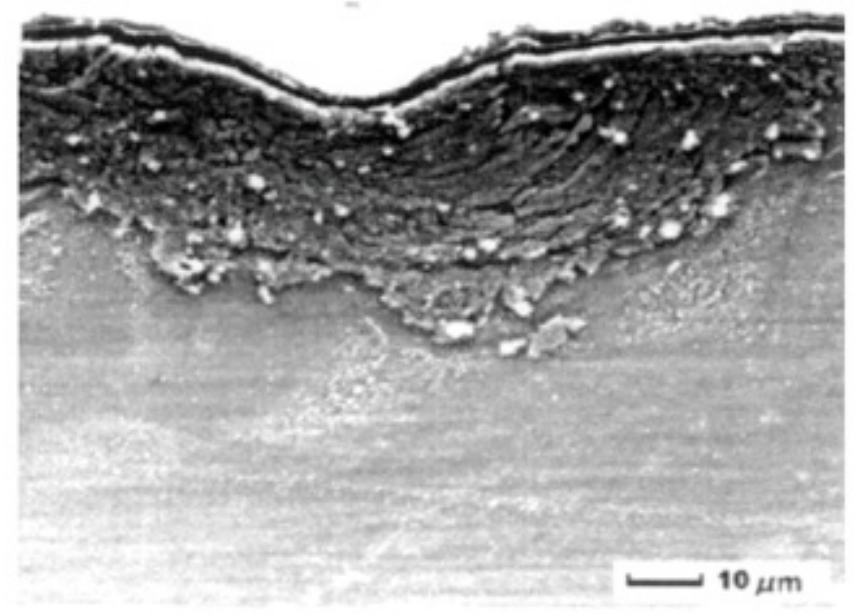

(b) Material B at $150^{\circ} \mathrm{C}$

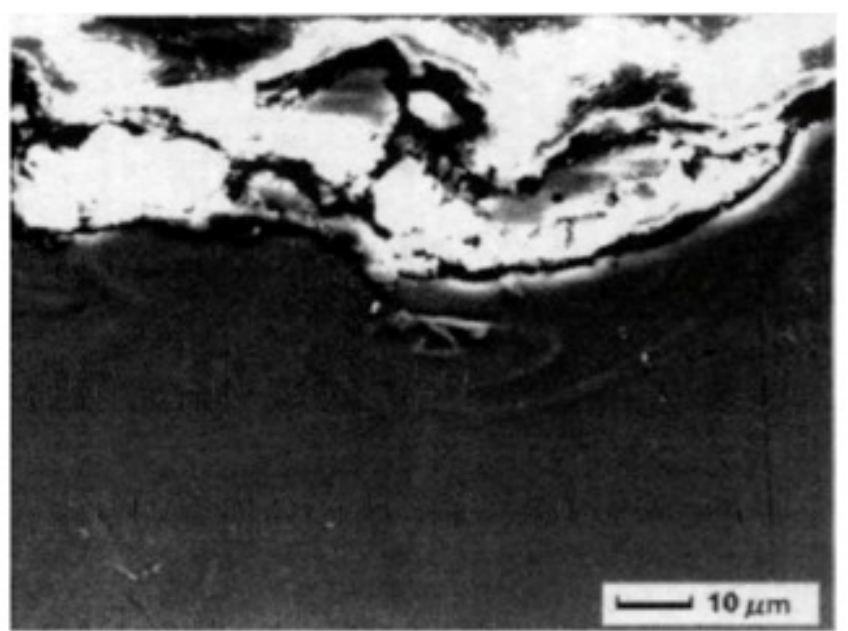

Fig. (3). Worn morphologies of ZA40 alloy samples with different amounts of RE.

high temperature. Oxide layer of samples without RE exhibited fragmentation. With the application of stress, the matrix had a larger plastic deformation, but the brittle oxide could not simultaneously arise the deformation of the matrix but cracks to be satisfied for the deformation in the matrix. Meanwhile, relative displacement caused the weak binding between substrate and oxide, even in detachment of the oxide from the substrate. Finally, large peelings were formed during cyclic loading. In the upper right corner of Fig. (2d), the matrix of the material was visible after the oxides were peeled off, showing the serious wearing. By contrast, the addition of RE in the high strength matrix of the alloy can sufficiently support the layer of oxide, thus mitigating plastic deformation under stress. The oxide layer can be satisfactory in combination with the matrix. It can be observed from Fig. (3a) that the oxide layers were tightly bonded to the substrate. Only few cracks existed within the oxide, so that only small peelings appeared during cyclic loading. In addition, the amount of wear loss was smaller than that of the material without RE.

\section{CONCLUSION}

1. The addition of 0.05 wt.\% RE to ZA40 alloy containing $\mathrm{Si}$ not only effectively refined the aluminium-based $\alpha$ dendrites of as-cast microstructure, uniformly distributed the $\mathrm{Cu}$-rich $\varepsilon$ phase, but also retained the precipitation amount of eutectic silicon, and refined the primary silicon.

2. The addition of 0.05 wt.\% mixed RE to ZA40 alloy containing Si enhanced the strength and ductility of alloy at ambient and elevated temperatures. The beneficial effects of RE were gradually apparent with an increase of temperature.

3. Under dry friction at $100^{\circ} \mathrm{C}$, the alloy without $\mathrm{RE}$ exhibited abrasive and adhesive wear, while the addition of RE resulted in the formation of abrasive wear. Under the dry friction at $150^{\circ} \mathrm{C}$, both kinds of alloys exhibited oxidative and oxide fatigue wear.

4. The addition of RE in the alloy can always improve the wear resistance of the materials, irrespective of the temperature $\left(100^{\circ} \mathrm{C}\right.$ or $\left.150^{\circ} \mathrm{C}\right)$. Since the addition of $\mathrm{RE}$ can refine the microstructure of the materials and improve the mechanical properties of materials..

\section{CONFLICT OF INTEREST}

The authors confirms that this article content has no conflict of interest.

\section{ACKNOWLEDGEMENTS}

Declared none.

\section{REFERENCES}

[1] Y.Y. Tan, "Research and application of high aluminum $\mathrm{Zn}$ based alloy", Special Casting \& Nonferrous Alloys, vol. 6, 30-31, 2001.

[2] Y.H. Liu, Z.M. Zhang, H.Z. Liu, et al. "Research status and application of zinc aluminum alloy", Foundry Technology, vol. 4244, 2001.

[3] G.Y. Liu, R. Zhang, L. Wang, et al. "Effects of stabilizing heat treatment on microstructures and creep behavior of $\mathrm{Zn}-10 \mathrm{Al}-2 \mathrm{Cu}-0.02 \mathrm{Ti}$ alloy", Transaction of Nonferrous Metal Society of China, vol. 23, 86-91, 2013.

[4] C.X. Xu, and P.L. Zhao, "Effects of mixed rare earth on mechanical properties of ZA27 alloy at high temperatures", Materials Science and Technology, vol. 7, 105 -108, 1999.

[5] H.J. Ni, B.D. Sun, H.Y. Jiang, et al. "Effects of rare earth solvent on secondary dendrite arm spacing of A356 alloy", Transactions of Nonferrous Metals Society of China, vol. 12, 940-943, 2002.

[6] L.I. Hy, Y. Liu, J.D. Hu, et al. "Hot deformation and processing map of ZA27 alloy", The Chinese Journal of Nonferrous Metals, vol. 22, 365-370, 2012.

[7] S.H. Liu, G.Q. Wang, and A.M. Wu, et al. "Effects of rare earth on the conductivity of pure aluminum", Transactions of Nonferrous Metals Society of China, vol. 10(3), 334-339, 2000.

[8] Z.J. Wang, and Z.S. Xu, "The crafts of Modification of Cu-Gr alloy using Ce”, Special Casting \& Nonferrous Alloys, vol. 3, 44-45, 1999.

[9] X. Cheng, D.M. Song, and Y.K. Wang, "Research of the casting process of high aluminum zinc-based hot-dip alloy", Yunnan Metallurgy, 40-42, 2009.

[10] A.M. Li, H.Y. Nan, and Y.J. Dai, "Effects of Si, Al and rare earth on microstructures and properties of casting zinc base alloy", Foundry, vol. 51, 695-697, 2002.

[11] Z.X. Luo, "Effects of rare earth on high aluminum $\mathrm{Zn}$ base alloys", Foundry Technology, (2), 26-29. 1989

[12] C.J. Yan, J.D. Wang, and J. Sun, "Effects of rare-earth oxides on the mechanical properties of high aluminum zinc-based alloy", Foundry Technology, vol. 842-844m 2006. 
[13] H.F. Zhao, F.L. Zhang, and P.L. Zhao, "Study on rare earth compounds strengthening the wear resistance of ZA27 alloy", Journal of the Chinese Society of Rare Earths, vol. 17, 227-230, 1999.
[14] E. Marui, N. Hasegawa, and H. Endo, et al. "Research on the wear characteristics of hypereutectoid steel", Wear, vol. 186-199, 1997.

[15] H. So, "Mechanism of oxidation wearing", Wear, vol. 1004-1015, 2002.

Received: July 25, 2014

Revised: August 4, 2014

Accepted: August 4, 2014

(C) Jiaming et al.; Licensee Bentham Open.

This is an open access article licensed under the terms of the Creative Commons Attribution Non-Commercial License (http://creativecommons.org/licenses/by-nc/3.0/) which permits unrestricted, non-commercial use, distribution and reproduction in any medium, provided the work is properly cited. 